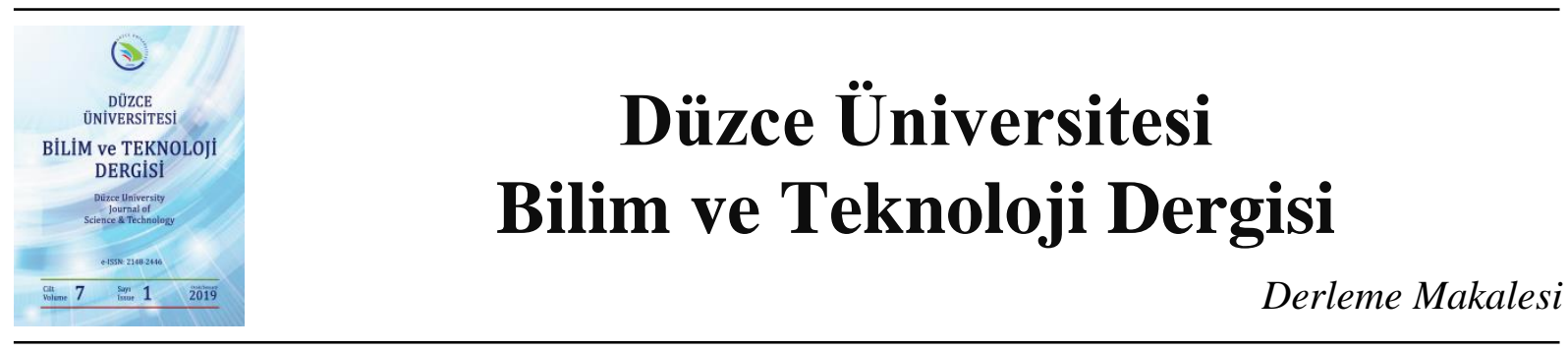

\section{Gözenekli Esnek Malzemelerin Bernoulli Prensibi Kullanılarak Temassız Taşınması Üzerine Literatür Taraması}

\author{
Şenol ERTÜRK ${ }^{\text {a, }}$, Fehmi ERZINCANLI ${ }^{\text {b }}$ \\ ${ }^{a}$ Makine Mühendisliği Bölümü, Mühendislik Fakültesi, Düzce Üniversitesi, Düzce, TÜRKİYE \\ ${ }^{b}$ Makine Mühendisliği Bölümü, Mühendislik Fakültesi, Düzce Üniversitesi, Düzce, TÜRKIYE \\ * Sorumlu yazarın e-posta adresi: senol14118@ogr.duzce.edu.tr
}

\begin{abstract}
ÖZET
Yapılan bu çalışmada Bernoulli prensibi ile çalışan tutucular ve uygulama alanları hakkında geniş kapsamlı bir araştırma yapılmıştır. Otomatik üretim süreçlerinde tutma aparatları ve yöntemleri bir çok ürünün taşınmasında önemli bir rol oynamaktadır. Göreceli olarak esnek ürünlerin temassız kaldırılıp taşınması için otomasyon uygulamaları, uygun tutucu eksikliğinden dolayı, sınırlıdır. Bu tür esnek malzemeler, esnekliğinin yanında genellikle, narin, gözenekli ve üzerlerinde kolaylıkla iz kalabildiğinden dolayı robot tutucuların çoğunun kullanılması mümkün değildir. Bu çalışmada değişken boyut, şekil ve ağırlıktaki esnek ürünlerin temassız kaldırılıp-taşınması için tutucuların yenilikçi yaklaşımları sunulmuştur. Temassız tutucular, tutucu ile ürün arasında Bernoulli prensibine uygun yüksek hızlı akış üretilmesi sonucunda oluşan vakum ile kaldırılması ilkesiyle çalışmaktadırlar. Çalışmanın sonunda bu tutucularla ilgili ileride yapılabilecek çalışmalar hakkında önerilerde bulunulmuştur.
\end{abstract}

Anahtar Kelimeler: Bernoulli tutucu, Temassız tutma, Radyal akış, Esnek malzemelerin taşınması

\section{A Literature Review on Non-Contact Handling of Porous Flexible Materials using Bernoulli Principle}

\begin{abstract}
In this study, an extensive research has been done about grippers working with the Bernoulli principle and applicationd fields. In automated production processes grasping devices and methods play a crucial role in the handling of many products. The application of automation for handling of non-rigid products are relatively limited due to lack of appropriate gripper. Most of the robot grippers are not easily applicable due to this type of products are often non-rigid, delicate, porous and easily marked. In this study, robot grippers work with principles of non-contact are introduced. These non-contact grippers are used to handle non-rigid products with variable size, shape and weight. The non-contact gripper operate using Bernoulli principle of generating a highspeed flow between the end effector and object surface thereby creating a vacuum which lifted the product. At the end of the study, suggestions were made about future studies on these grippers.
\end{abstract}

Keywords: Bernoulli gripper, Non-Contact Handling, Radial Flow, Handling of Non-Rigid Materials 


\section{GiRis}

Robotların üretim sektöründe kullanılabilmeleri için yapacağı işe özel tutucular/aparatlar geliştirilmesi gerekmektedir. Aksi halde robotik sistem için yapılan yatırımlar boşa gidecektir. Robotlar, uygun tutucu/aparatı olmadan bir hiç durumundadır. Bu sebepten hem akademik olarak hem sanayi olarak çok çeşitli tutucular geliştirilmiştir ve geliştirilmektedir. Günümüze kadar yapılan bu çalışmalardan sağlık alanında kullanılması düşünülen tutucuların daha önce hangi alanda kullanıldığına yönelik bir çalışma sunulmuştur. Bunlardan en önemlisi dokunmasız olarak tutuculuk görevi yapan Bernoulli prensibine göre çalışan ve Bernoulli olarak da bilinen ilk akademik çalışmaları Erzincanl1 [1] tarafindan yapılan robot tutucusudur. Bu tip tutucu öncelikle gida endüstrisinde kullanılmaya çalışılmıştır. Bu konuda çeşitli robotik tutucularla ilgili literatür çalışması incelenmiştir. Otomatik üretim süreçleri, kavrama aletleri ve yöntemleri esnek malzemelerin taşınmasında önemli rol oynamaktadır. İmalat süreçlerinde gıda, tıbbi ve tekstil ürünlerine temas, üründe zarar ve kirlenmelere neden olabileceğinden istenmeyen bir durum oluşmaktadır. Bu nedenle birçok temassız taşıma işlemleri önerilmiş ve etkisi ispatlanmıştır. Bu uygulamaların en tipik örneği Bernoulli prensibine dayalı Bernoulli diğer bir ifadeyle temassız tutuculardır. Temassız tutucular, hava akışı ile yukarıya doğru bir kaldırma kuvveti oluşturur. Bu kaldırma kuvveti, tutucunun altına yerleştirilmiş ürünü her hangi bir temas olmadan kaldırmak için kullanılır. İnsan eliyle veya temaslı tutucular ile işlenen gıda ürünlerinde üç çeşit kirlilik oluşmaktadır. Bunlar, toksik kirlilik, bakteri veya mantar kirliliği ve üründeki renk değişimidir. Bu yüzden gida ürünlerinin geleneksel temaslı tutucular ile tutulması uygun değildir. Bernoulli prensibine uygun çalışan tutucular hakkında akademik alanda yapılmış çalışmalar aşağıdaki paragraflarda özetlenmiştir. Rawal ve arkadaşları [2], bisküvi imalat endüstrisinde kullanılmak üzere ürünlere herhangi bir mekanik temas olmadan taşınması için dikdörtgen kesitli bir tutucu tasarlamıştır. Bu tutucu, ürün ile arasında Bernoulli prensibine uygun yüksek hızlı akış üretilmesi sonucunda oluşan vakum ile kaldırılması ilkesiyle çalışmaktadır. Gıda ürünlerinin taşınması sırasında doğrudan temastan dolayı üründeki kirlenme riskini önlemek için temassız tutucuya ihtiyaç duyulmuştur. Mevcut çalışma, bisküvi endüstrisinde radyal akış nozullarının kullanılabilme olasılığını araştırmıştır. Sam ve Nefti [3], Sam ve Buniyamin [4], geliştirdikleri tutucu ile yuvarlak, düz ve düzensiz şekilli gıda ürünleriyle deney yapmışlardır. Yuvarlak nesne için ağırlık aralığının, düz ve düzensiz şekilli nesnelerle karşılaştırıldığında büyük ölçüde azaldığı sonucuna varılmıştır. Ağırlık azalmasının nedeni dairesel nesnenin yüzey düzgünlüğüdür. Deneyler sonucunda nesnenin yüzey pürüzlülüğü arttıkça kaldırma kabiliyetinin azaldığı sonucu ortaya çıkmıştır ve düzensiz şekilli gıdaları kaldırabilmek için düz şekilli gıda ürünlerinden daha yüksek hava akış hızına ihtiyaç duymuşlardır. Toklu ve Erzincanlı [5] , esnek malzemeleri kaldırmak için temassız tutucunun radyal akışı için sayısal model geliştirmiştir. Deneysel sonuçlar, hacimsel hava akış hızının artması ile tutucu ile kaldırılan nesne arasındaki boşluk aralığının arttı̆̆ını ve Reynold sayısının artması ile negatif basıncın arttığını ortaya çıkarmıştır. Petterson ve Ohlsson [6], deforme olabilen yüzey kullanarak düzlemsel ve üç boyutlu gıda ürünlerinin taşınması için Bernoulli prensibi ile çalışan bir tutucu test etmiştir. Deforme olabilen yüzey, biçimlendirilerek kaldırma kuvveti oluşturmak için kullanılmıştır. Kaldırma kuvvetini arttırmak için küçük bir şekillendirme derinliği değerine gerek duyulmuştur. Bu çalışmaya göre kaldırma kuvveti, biçimlendirme derinliği arttıkça artmaz, bu yüzden optimum değer korunmalıdır. Biçimlendirme derinliği arttıkça, optimum değere ulaştığında kuvvet artışı ortaya çıkmaktadır, kuvvet biçimlendirme derinliği ile azalma eğilimi gösterir. Nedeni tutucunun dış kenarındaki sürtünme kaybıdır. Petterson'un bu çalışmasında, 70 gr.' dan daha az ve oransal düzgün yüzeye sahip bir nesne için Bernoulli prensibi ile çalışan üç boyutlu bir tutucunun uygun olduğu önerilmektedir. Petterson, peynir dilimini yaptığı deney sonucunda 96 1/dk hava akış hızında kaldırılabildiğini bulmuş, fakat kaldırdıktan sonra kaymış ve dilim hava jetinin girmesi ile yırtılmıştır. 
Li ve arkadaşları [7], vortex tutucu ile geleneksel Bernoulli etkili tutucunun enerji tüketimini deneysel olarak analiz etmiş ve karşılaştırmıştır. Aynı çalışma şartlarında vortex tutucunun güç tasarrufu açısından daha avantajlı olduğu sonucu çıkarılmıştır. Tutucunun basınç dağılımı, deformasyon ve iş parçasının iç stresleri aynı seviyededir. Vortex tutucunun üzerindeki yüzey pürüzlülüğü Bernoulli etkili tutucudan daha çok etkilenmişir. Journee ve Chen [8], Bernouli prensibi ile çalışan pimli bir tutucu önermiştir. Tutucu da konkav nozula benzer bir hava yönlendirici plaka kullanılmıştır. Bu tutucu, büyük plakaları taşımak için kullanılmaktadır ve yüzeyi gerektiği kadar genişletilebilmektedir. Davis ve arkadaşları [9], dilimlenmiş domates ve salatalık tutmak için hava yönlendiricili bir tutucu geliştirmiştir. Nesnenin üzerine akan kuvvetli hava akışının, kaldırılan nesneye direk teması ile oluşabilecek hasarın önlenmesini yönlendirici ile çözmüştür. Yönlendirici, nozula bağlanır ve hava akışını eksenel yönden radyal yön boyunca $90^{\circ}$ saptırır. Fakat dezavantajı, nesne tutulduğu zaman yönlendiricide Bernoulli etkisi olmadığından ürünün temas etmesidir. Bu yüzden tutucu tamamen temassız değildir. Kaldırılan ürünün tutucuya temasını önlemek için tutucunun yüzeyine bir dizi kaburga yapmıştır. Davis $6 \mathrm{~mm}$ ve $10 \mathrm{~mm}$ çaplı hava yönlendiricili tutucuları test etmiş ve sonucunda $6 \mathrm{~mm}$ çaplı hava yönlendiricili tutucunun $10 \mathrm{~mm}$ çaplıya göre daha çok kaldırma kuvveti elde ettiğini tespit etmiştir. Dini ve arkadaşları [10] geliştirdiği Bernoulli prensibi ile çalışan farklı bir tutucu geliştirmiştir. Küçük açılı yön değiştirici ile $(\alpha)$ kaldırma kuvvetini arttırmak, deri yüzeyindeki izleri azaltmak ve tutucunun performansını arttırmak için tutucu yüzey üzerine radyal Venturi kanallar açmıştır. Hava yön değiştirici açıları, $60^{\circ}$ ve $30^{\circ}$ olan tutucu yüzeylerinde radyal oluklar (Venturi kanallar) vardır. Deney sonucunda hava yönlendiricisi olmayan tutucunun en iyi performansı sağladığ1 sonucuna varmıştır. Saptırma açısı $60^{\circ}$ olan yönlendiricili tutucu, tutma kuvvetine çok küçük bir değer sağlamıştır. Saptırma açısı $30^{\circ}$ olan yönlendiricili tutucu, önemli kaldırma kuvveti göstermiştir. $30^{\circ}$ eğimde ve Venturi kanallı yönlendirici plakalı tutucu deri yığınlarını tutarken çok iyi davranış göstermiş̧tir. Trommelen [11], Bernoulli prensibine dayalı medikal bir tutucu geliştirmiş ve hava akış hızındaki artış, tutucu yüzeyin ve nozulun yarıçapının kaldırma kuvvetine pozitif etki yaptığını belirtmiştir. Tutma sırasında dokuların güvenliğini sağlamak için hava akışının yönü üzerine çalışmışır. Tutucunun hasta karnına kolay yerleştirme ve çıkarma için genişletilebilir ve daraltılabilir bir tutucu tasarlamıştır. Deney sonuçları, $128 \mathrm{~m} / \mathrm{s}$ ' den daha yüksek bir hızın doku hasarına neden olduğunu göstermiştir. Yazar, finalde Bernoulli prensibi ile deney sonuçlarını karşılaştırmıştır. Paivanas ve Hassan [12], sert, yarı iletken levhaların temassız taşınması için radyal olarak uzaklaşan hava akımı üzerine çalışmıştır. İlk tasarım değişiklikleri radyal hava akışının levha yüzeyine doğrudan çarpmasını önlemek için bir uç milin kullanımını içermektedir. Grutzeck ve Kiesewetter [13], mikro parçaların taşınmasında Bernoulli etkisinin kullanımını analiz etmiştir. Grutzeck, kapiler ve Bernoulli etkisini karşılaştırmıştır. $0.72 \mathrm{l} / \mathrm{dk}$. ile $2 \mathrm{l} / \mathrm{dk}$. arasında ki hava akışı ve yaklaşık 50 mikron civarında aralık yüksekliğinin Bernoulli etkisi oluşturduğunu tespit etmiştir. Eğer aralık ölçüsü 25 mikron dan küçükse, hava akımının, tutucudaki basınç kuvvetini ittiği iddia edilmiştir. Bernoulli etkisine dayalı, gıda ürünlerinin taşınması için temassız tutucuyu tasarlayarak geliştiren ve kullanan ilk kişi Erzincanlı [1] olmuştur. Erzincanlı, tutucu yüzey ile ürün yüzeyi arasında yüksek hızlı bir hava akışı ile nesneyi havaya kaldıracak vakum oluşturmuştur. Erzincanlı, esnek malzemelerin kaldırılması için standart nozul tasarlamıştır [14]. Fakat standart nozul ile esnek malzemelerin kaldırılmasında bazı sınırlamalar tespit etmiştir. Nozuldan gelen basınçlı hava akışının narin, esnek malzemeye direk çarpması sonucunda yüzeylerinde iz bıraktığını ve ürünlere zarar verdiğini ifade etmiştir. Bu da ürün kalitesi açısından istenmeyen olumsuz algılara neden olabilmektedir. Erzincanlı, hem narin yapılı hem de hava geçirgen özelliği olan malzemelerin kaldırılmasında yeni bir nozul geliştirmiştir. Bu nozul, üzerine monte edilen koni şeklinde hava yönlendirici ile malzemenin üzerine direk gelen basınçlı havanın yönünü değiştirerek kaldırma sırasında malzemenin yüzeyinde oluşabilecek izleri ve hasarları ortadan kaldırmıştır. Erzincanlı' nın nozul tasarımına göre $100 \mathrm{kPa}$ manometre basıncı, 35-175 gr. değişik boyuttaki nesneleri kaldırmak için yeterlidir. Hava akış hızı arttıkça esnek nesnelerin bükülmesi ile 
hava dışarıya kaçtığı için esnek nesneleri kaldırmak için optimum hava akışı gereklidir. Eğer akış hızı düşükse kaldırma esnasında nesne yatay olarak kaymaktadır. Özçelik ve Erzincanlı [15], dokuma kumaşlarını ve diğer malzemeleri temassız tutucu kullanarak kaldırmak üzere deneysel çalışmalar yapmıştır. Yatay yöndeki taşıma hızı çalışılmıştır. Deney sonuçları optimum hava basıncına ihtiyaç olduğu sonucu ile sonuçlanmıştır. Eğer hava basıncı artarsa dokuma kumaşlar tutucu yüzeyinden kaymaktadır. Optimum yüksek basınç değeri ile kumaşlar yüksek hızda hareket edebilirler. Jaiswal ve Kumar [16], çalışmasında vakum tipi tutucu plaka ile ürün yüzeyi arasında yüksek hızlı akış oluşturulması sonucunda Bernoulli prensibi ile ortaya çıkan vakum ile değişken büyüklük, şekil ve ağırlıktaki paketlenmemiş gıda ürünlerinin taşınması için yenilikçi bir yaklaşım sunmuştur. Callies ve Fronz [17], vakum kupalı, çoklu bağlantılı tutucuların tekrarlamalı modelleme ve kontrolü üzerinde çalışmıştır. Optimum kontrol probleminin yapısal özelliklerini ortaya çıkarmıştır. Mantriota [18], bir vakum tutucu ile nesnelerin tutulması üzerinde çalışma gerçekleştirmiştir.Vakum kupası ile nesne arasındaki temas kuvvetlerini belirlemek için matematiksel bir model önermiştir. Temel amacının, hareket sırasında cismin sıkı bir şekilde kavranmasını sağlamak için statik sürtünme katsayısının minumum değerini ve vakum seviyesini belirlemek olduğunu ifade etmiştir.

Brun ve Melkote [19], koni milli bir Bernoulli tutucunun hesaplamalı akışkanlar dinamiğini oluşturmuş̧tur. Tutucu modelini kullanarak oluşturulan hava akışını, basınç dağılımını ve kaldırma kuvvetini tahmin etmiştir. Possamai ve arkadaşları [20], radyal bir dağıtıcıdaki sıkıştırılamaz, laminer ve izotermal akışı farklı Reynold sayısı kombinasyonları ile araştırmıştır. Osyczka [21], çok amaçlı bir evrimsel algoritma kullanarak robot tutucu tasarımını optimize etmiş ve tutma problemlerini farklı konfigürasyonlarla çözmüştür. Lanni ve Ceccarelli [22], robot tutucuda çok amaçlı bir optimizasyon üzerinde çalışmışlardır. Çalışma alanı ile ilgili olarak tutma indeksi, hız, ivme ve tutma mekanizması dikkate alınarak iki parmaklı kavrama mekanizması optimize edilmiştir. Datta ve Deb [23], Tutulan nesneye zarar veren tutucu kararlılığını sağlamak için robotik tutucu tarafından nesneye uygulanan kuvvetleri optimize etmiştir. Amacı basınçtaki farkın ve iletim oranının en aza indirgenmesini içermektedir. Bu çalışmanın amacı literatürde Bernoulli prensibi ile çalışan tutucuların çalışma prensibi ve uygulama alanları hakkında bir araştırma yaparak geliştirilecek yeni tutucular hakkında fikir sahibi olmaktır. Araştırma neticesinde Bernoulli prensibi kullanılarak tasarlanmış tutucuların çalışması, uygulama alanları hakkında bilgiler verilmiş ve önerilerde bulunulmuştur.

\section{TUTUCU PATENTLERI}

Literatürde akademik çalışmaların yanında geliştirilmiş ve patentleri alınmış temassız tutucular da mevcuttur. Bernoulli prensibi ile çalışan bu tutucular ile ilgili alınan patentler aşağıda sunulmuştur.

\section{A. PATENT (BENJAMIN 1969)}

Bernoulli tutucu, genellikle temassız taşıma için kullanılır. Rijid, yuvarlak, yarı iletken nesneleri Bernoulli prensibi ile kaldıran ilk patent Benjamin tarafından 1969' da alınmıştır. Bu tutucu da kabul edilebilir akış ve tasarım koşulları altında eksenel olarak yönlendirilmiş bir hava akışı, tutucu yüzey ile nesne arasında negatif bir basınç bölgesi oluşturmak için radyal yönde saptırılmıştır. Bu teknik, ince yarı iletken malzemelerden gıda ürünlerine kadar birçok çeşit malzemelerin taşınmasına olanak sağlamaktadır. 
Şekil 1' de gösterilen tutucu bir santimetre kare düz nesneleri kaldırmak için kullanılmıştır. Tutucu yüzey, nesne yüzeyine paralel olmalıdır. Hava, probun bir ucundan girer ve nesne Bernoulli prensibi ile kaldırılmaktadır.

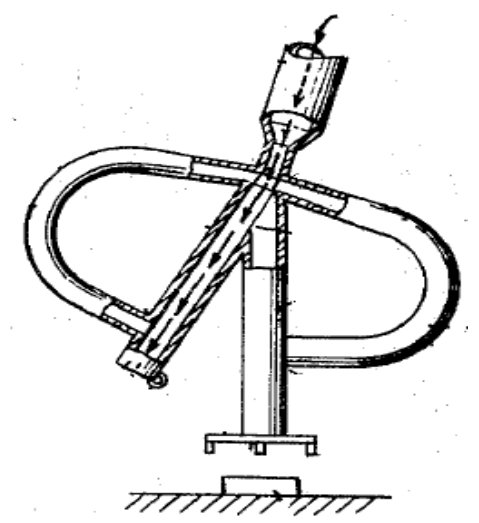

Şekil 1. Problu tutucu [24].

\section{B. PATENT (MAMMEL 1969)}

Bu tutucu, yarı iletken dilimlenmiş nesneleri kaldırmak için tasarlanmıştır. Tutucu, iş parçası üzerinde sabit bir yönde yatay bir kuvvet uygular. Çalışma yüzeyi ve çıkıntılı basamak birlikte kaldırma başını oluşturmaktadır. Akışkan, çalışma yüzünün ve basamağın birleşiminde biten kanal ile kaldırma kafasına kadar ulaşır. Bernoulli ilkesi ile iş parçası kaldırılır. Çalışma yüzeyindeki klavuz pimler tutulan nesnenin kaymasını önlemektedir. Tutucunun şematik diyagramı Şekil 2' de gösterilmektedir.

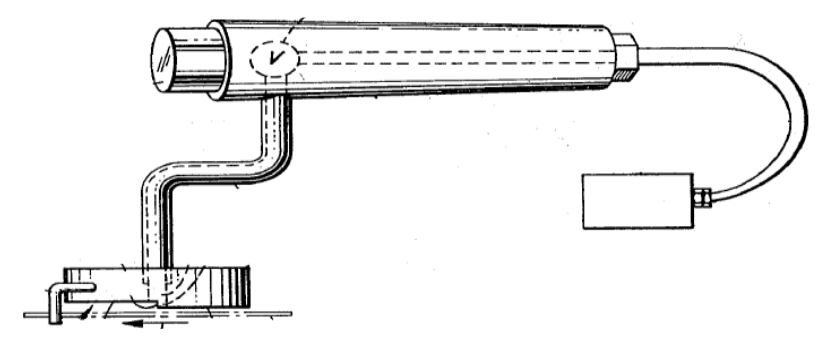

Şekil 2. Basamaklı tutucu [25].

\section{PATENT (KUMA 1988)}

Bu patentte, bir plakanın fiziksel temas olmaksızın akışkan vasıtasıyla taşınması için geliştirilmiş bir aparat sunulmuştur. Tutucu, Bernoulli prensibi ile plakaları kaldırmak için kullanılmaktadır. Tutucudaki hava akışı, Şekil 3' te okla gösterilmiştir. Kaldırma için kullanılan basınçlı havanın sistemden dışarı kaçmasına izin verilmemektedir. Emiş borusu ile emilir. Emme tüpünün kenarları, kaymayı önlemek için nesnenin kenarlarına kadar uzatılmıştır. 


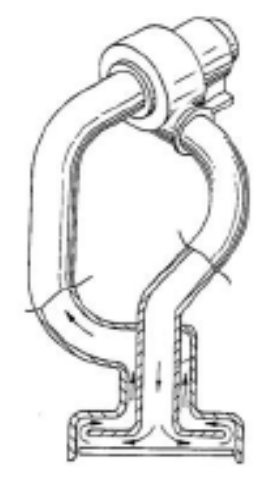

Şekil 3. Kademeli yüzlü tutucu [26].

\section{PATENT (CORLOMAGNO 1990)}

Bu patentte Şekil 4' te gösterildiği gibi tutucu, yüksek sıcaklıklarda katı duvarlara temas etmeden cam levhalara kaldırma kuvvetleri uygulamak için önerilmiştir. Cam levha ile söz konusu duvar arasında bir gaz yastığı oluşturulmuştur. Kullanım alanına ve ihtiyaçlara göre farklı biçimli tutucular geliştirilmiştir.

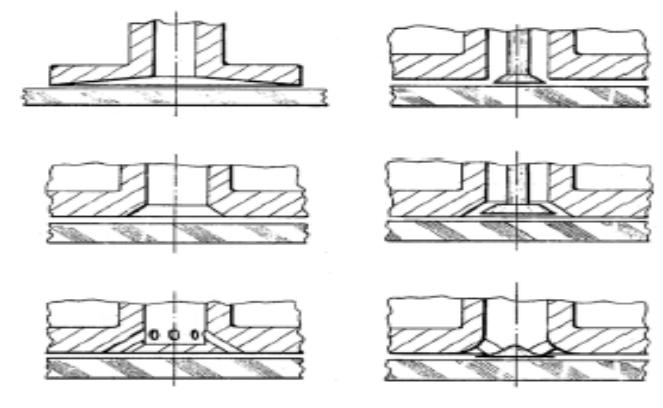

Şekil 4. Farklı biçimli tutucular [27].

\section{E. PATENT (OKUGI 2002)}

Şekil 5' de görülen tutucunun yüzey bölgesinde konkav nozula benzeyen bir hava yönlendirme plakası kullanılmıştır. Bu tutucu, büyük plakaları tutmak için kullanılır ve yüzeyi gerektiği kadar genişletilebilir. Silikon plakalardan gida malzemelerine kadar esnek ve esnek olmayan malzemelerin farklı çeşitlerini tutmaya olanak sağlamaktadır. 


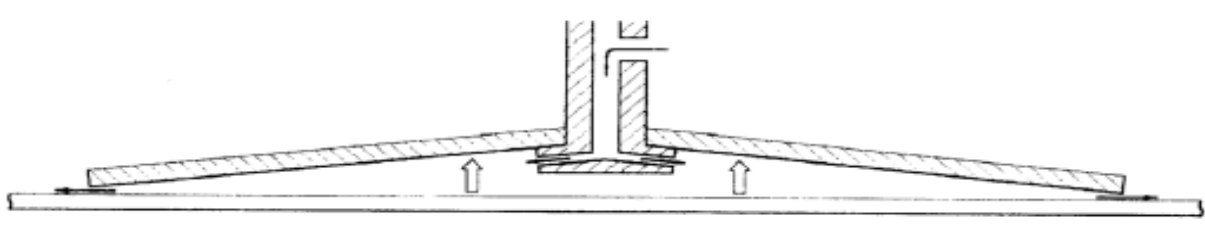

Şekil 5. Genişletilebilen sistemli tutucu [28].

\section{BERNOULLI PRENSIBII}

Bernoulli prensibi ile çalışan tutucu, merkezinde dairesel bir delik olan dairesel tutucu yüzeyden oluşmaktadır (Şekil 1). Akışkan, merkezi delik boyunca akmaktadır ve dairesel deliğin merkezine yerleştirilmiş olan tutucu yüzeyden dışarı çıkmaktadır. Bernoulli prensibi, hem sıvı hem de hava ile çalışabilmektedir. Yapılan çalışmaların geneli, hava ile çalışan Bernoulli tutuculardır. Tutucu yüzey, bir nesneye yaklaştırıldığı zaman hava, tutucu yüzey ile nesne arasındaki dar aralıktan tutucu yüzeyin şekli üzerinden radyal olarak dışarı akmaktadır. Bernoulli prensibi, enerjinin korunumu yasasından çıkarılabilir. Buna göre nesne ile tutucu yüzey arasındaki dar bölgede akışkanın hızı arttıkça o bölgedeki basınç azalmaktadır. Bernoulli prensibi Eşt. 1'de verilmiştir;

$\left(\frac{1}{2} \rho v^{2}+P\right)_{1}=\left(\frac{1}{2} \rho v^{2}+P\right)_{2}$

$\rho:$ hava yoğunluğu, v: hızı, P: tutucunun 1. veya 2. bölgedeki basıncını vermektedir (Şekil 6). Nesne üzerindeki toplam kaldırma kuvveti, sistemin çekme ve itme kuvvetlerinin farkına eşittir.

$F_{\text {top }}=F_{\text {çekme }}-F_{\text {itme }}$

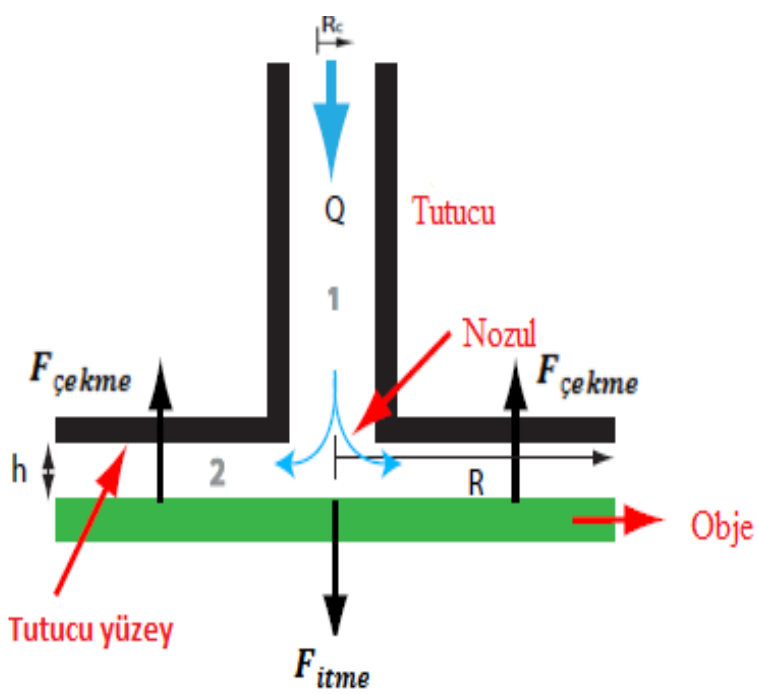

Şekil 6. Bernoulli prensibi ile çalışan tutucu [11]. 


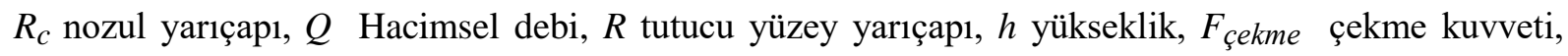
$F_{\text {itme }}$ itme kuvveti belirtmektedir.

Eğer toplam kaldırma kuvveti nesnenin ağırlığından daha büyük ise nesne kaldırılabilir. Nesnenin tutulacağı $h$ yüksekliği, kütlenin korunumu kullanılarak hesaplanabilir. Sıfırdan büyük bir $h$ yüksekliği, nesnenin tutucuya dokunmadan kaldırılabildiğini göstermektedir. Geçmişte farklı ağırlık ve büyüklükteki nesneleri kaldırabilen tutucular mevcuttur. Literatürde tanımlanan en küçük tutulan nesne, nozul yarıçapı $0,1 \mathrm{~mm}$ ve tutucu yüzey yarıçapı $4 \mathrm{~mm}$ olan bir tutucu ile tutulan $4 \times 4 \mathrm{~mm}$ boyutlarındaki slikon çiptir [13]. 2 1/dk bir hava debisi ile toplam kaldırma kuvveti $5 \mathrm{Nm}$ değerine ulaşmıştır. Literatürde en büyük kaldırma kuvveti, 4 mm' lik bir nozul yarıçapı, $45 \mathrm{~mm}$ tutucu yüzey yarıçapı ve 288 1/dk. hava akışı ile $50 \mathrm{~N}$ olarak bulunmuştur [10].

Bernoulli tutucu ile tutulan bir nesnenin üzerindeki kuvvetlerin etkisi, tutucunun merkezinden uzaklaştıkça azalmaktadır. Ayrıca tutucuda, havanın tutulan nesneye direk temasını önlemek için eksenel yönde akan havanın yönünü radyal yöne doğru değiştiren yönlendirici kullanılmalıdır. Aksi halde nozuldan çıkan hava direk esnek nesneye temas edeceğinden nesnede titreşim meydana gelip sonucunda da nesne yüzeyinde deformasyona neden olabilmektedir. Eğer nesne sabit pozisyonda değilse ise uçabilir [29].

\section{SONUC}

Yapılan bu çalışmada, narin ve esnek ürünlerin taşınması için tasarlanmış, Bernoulli prensibi ile çalışan temassız tutucular ve uygulama alanları detaylı bir şekilde incelenmiş ve şu sonuçlar çıkarılmıştır.

- Geliştirilen temassız tutucular, düzgün yüzeyli, sert ve esnek malzemelerin taşınmasında başarıyla uygulanmıştır.

- Bisküvi numunelerinin geliştirilen tutucu ile temassız bir şekilde taşınması sağlanmıştır.

- Değiş̧ken büyüklük, şekil ve ağırlıktaki paketlenmemiş gıda ürünlerinin temassız taşınması için başarılı bir tutucu tasarlanmış ve uygulanmıştır.

- Gıda endüstrisinde yaygın olarak bulunan hassas dilimlenmiş meyve ve sebze ürünlerinin temassız taşınması için bir tutucu geliştirilmiştir.

- Deri katmanları Bernoulli prensibi ile geliştirilen bir tutucu ile başarılı bir şekilde kaldırılmıştır.

- Laparoskopik cerrahide doku hareketi için Bernoulli tutucunun uygulama imkanı, tasarlanan açılabilir ve katlanabilir bir tutucu ile araştırılmıştır.

- Narin ve hava geçirgen özelliği olan nesneler, zarar görmeden tasarlanan hava dağıtıcılı bir tutucu ile başarılı bir şekilde kaldırılmıştır. 
- Üç boyutlu gıda ürünlerin kaldırma maliyetlerini azaltmak için Bernoulli prensibi ile çalışan bir tutucu geliştirilmiştir.

- Dokuma kumaşları, Bernoulli prensibi ile geliştirilen bir tutucu ile kaldırılmış ve bu tutucunun yatay yöndeki taşıma hızları incelenmiştir.

- Ürünlerin temassız olarak havaya kaldırılması için radyal akış ve basınç dağılımında negatif değer bölgelerini gösteren sayısal bir model geliştirilmiştir.

- Geliştirilen Bernoulli tutucu ile enerji tüketimi, basınç dağılımı, iş parçasının deformasyonu, iç gerilmeleri ve yüzey pürüzlülüğünden kaynaklanan etkiler deneysel olarak incelenmiştir.

- Temassız tutucular çok farklı şekil, ağırlık ve kırılganlıktaki nesnelerin tutulabilmesine olanak sağlamıştır.

- Sert, yarı sert ve esnek nesneler Bernoulli prensibi ile çalışan tutucular ile zarar görmeden taşınabilmektedir.

- Minimum hava tüketimi sayesinde düşük enerji maliyetine sahiptirler.

- Yüksek emiş kuvvetlerine rağmen düşük gürültü seviyesindedirler.

- Bernoulli tutucunun sayısal modellemesi konusunda çok sınırlı çalışmalar yapılmıştır. Tasarlanmış tutucuların sayısal modelleri genişletilmelidir.

- Gıdaların taşınması ve nesne üzerindeki basınç dağılımı ile ilgili sadece birkaç araştırmacı Bernoulli tutucu geliştirmiştir.

- Uygulanan hava jeti ile nesnelerin kaymasını önlemek için temassız Bernoulli tutucu üzerindeki tutucu yüzeyin optimize edilmesi gerekmektedir.

- Kaldırılan nesnenin direk üzerine gelen basınçlı havanın, ürüne çarpmadan dağıtılması için hava dağıtıcı sistemli tututular tasarlanmalı ve geliştirilmelidir.

Uluslararası literatürün değerlendirilmesi esnek ve narin ürünlerin zarar görmeden taşınması için temassız ve uyarlanabilir tutuculara ihtiyaç olduğunu göstermiştir. Temassız tutucular hakkında yapılan akademik ve ticari çalışmalar her geçen gün artmaktadır. Bu sistemler çeşitli malzemelerin zarar görmeden temassız taşınması için çalışılması ve geliştirilmesi gereken konular arasındadır. İlerleyen teknoloji, düşen maliyetler ve artan ihtiyaçlar neticesinde önümüzdeki yıllarda esnek ve narin malzemelerin zarar görmeden temassız bir şekilde kavranması ve taşınması için tutucuların daha da geliştirileceği öngörülmektedir.

TEȘEKKÜR: Bu çalışma Düzce Üniversitesi Bilimsel Araştırma Projeleri tarafından desteklenmiştir (Proje no : 2018.06.05.675). 


\section{KAYNAKLAR}

[1] F. Erzincanl1, "A non-contact end effector for roboting handling of non-rigid materials," Ph.D. dissertation, Department of Manufacture and Marketing, Salford University, Salford, UK, 1995.

[2] B. R. Rawal, V. Pare and K. Tripathi, "Development of non-contact end effector for handling bakery products," Internationaljournal of advanced manufacturing technology, vol. 38, pp. 524-528, 2008.

[3] R. Sam and S. Nefti, "Design and feasibility tests of multi-functional gripper for handling variable shape of food products," In Published in systems man and cybernetics, IEEE International conference, Istanbul, Turkey, 2010, pp. 1267-1172.

[4] R. Sam and N. Buniyamin, "A Bernoulli principle based flexible handling device for automation of food manufacturing processes," Int. Conf. Control. Autom. Inf. Sci. (ICCAIS), Ho Chi Minh City, Vietnam, 2012, pp. 214-219.

[5] E. Toklu and F. Erzincanl1, "Modeling of radial flow on a non-contact end effector for robotic handling of non-rigid material," J. Appl. Res. Technol., vol. 10, no. 4, pp. 590-596, 2012.

[6] A. Petterson and T. Ohlsson, "A Bernoulli principle gripper for handling of planar and 3D (food) products," Ind. Robot An Int. J., vol. 37, no. 6, pp. 518-526, 2010.

[7] X. Li, N. Li, G. Tao and H. Liu, "Experimental comparison of Bernoulli gripper and vortex gripper,” Int. J. Precis. Eng. Manuf., vol. 16, no. 10, pp. 518-526, 2015.

[8] M. Journee and X. Chen, "An investigation into improved non-contact adhesion mechanism suitable for wall climbing robot," IEEE Int. Conf. Robot. Autom. Shanghai Int. Conf. Cent., Shanghai, Chine, 2011.

[9] S. Davis, J.O. Gray and D.G. Caldwell, "An end effector based on the Bernoulli principle for handling sliced fruit and vegetables," Robot. Comput. Integr. Manuf. vol. 24, no. 2, pp. 249$257,2008$.

[10] G. Dini, G. Fantoni and F. Failli, "Grasping leather plies by Bernoulli grippers," CIRP Ann. Manuf. Technol., vol. 23, no. 4, pp. 21-24, 2009.

[11] M. Trommelen, "Development of a medical Bernoulli gripper," M.S. thesis, Department of Biomedical Engineering, Delft University of Technology, Delft, Netherlands, 2011.

[12] J. A. Paivanas and J. K. Hassan, "Air film system for handling semiconductor wafers," IBM Journal of Research and Development, vol. 47, no. 8, pp. 361-375, 1979.

[13] H. Grutzeck and L. Kiesewetter, "Downscaling of grippers for micro assembly," Microsyst. Technol., vol. 8, no. 1, pp. 27-31, 2002. 
[14] F. Erzincanl1, J.M. Sharp and A.M. Dore , "Grippers for handling of non-rigid food products," Proc. EURISCON' 94 , Malaga, 3, pp. 798-806, 1994.

[15] B. Özçelik and F. Erzincanl, "Examination of the movement of a woven fabric in the horizontal direction using a non- contact end effector," Int. J. Adv. Manuf. Techno., vol. 25, no. 5, pp. 527-532, 2005.

[16] A. K. Jaiswal and B. Kumar, " Design constraints of vacuum cup gripper an important material handling tool,"' International Journal of Science and Technology, vol. 7, no. 1, pp. 1-8, 2017.

[17] R. Callies and S. Fronz, " Recursive modelling and control of multi link manipulators with vacuum cup grippers," Math. Comput. Simul., vol. 79, pp. 906-916, 2008.

[18] G. Mantriota, "Theoretical model of the grasp with vacuum cup gripper," Mech. Mach. Theory, vol. 42, pp. 2-17, 2007.

[19] X.F. Brun and S.N. Melkote, "Analysis of stresses and breakage of crystalline silicon wafers during handling and transport', Solar Energy Materials and Solar Cells, vol. 93, no. 8, pp. 12381247, 2009.

[20] F.C. Possamai, R.T.S. Ferreira and A.T. Prata, "Pressure distribution in laminar radial flow through inclined disks', Int. J. Heat Fluid Flow, vol. 22, no. 4, pp. 440-449, 2001.

[21] A. Osyczka, "Evolutinory algorithms for single and multicriteria design optimization", Structural and Multidisciplinary Optimization, vol. 24, no. 1, pp. 88-89, 2002.

[22] C. Lanni and M. Ceccarelli, "An optimization problem algorithm for kinematic design of mechanisms for two finger grippers", The Open Mech.Eng.J., vol. 3, no.2, pp.49-62, 2009.

[23] R. Datta and K. Deb, "Multi-objective design and analysis of robotic gripper configuration using an evolutionary classical approach", In pro 13th annual conference, genetic evolutionary comput. Dublin, irerland, 2011, pp. 1843-1850.

[24] J. M. Benjamin, "Pneumatic probe for handling flat objects," U.S. Patent 3425 736, Feb. 4, 1969.

[25] W. K. Mammel, "Pickup device for supporting work piece on a large of fluid," U.S. Patent 3 431 009, March 4, 1969.

[26] T. Kuma, "Method of supporting and/or conveying a plate with fluid without physical contact," U.S. Patent 4735449 Apr. 5, 1988.

[27] G. M Carlomagno, "Process for Applying Forces to Glass Sheets, in Particular at a High Temperature," U.S. Patent 4920520 May 1, 1990.

[28] Y. Okugi, "Substrate transfer apparatus,” U.S. Patent 6379103 Apr. 30, 2002. 
[29] Food Refrigeration and Process Engineering Research Center (2010). Airflow (Bernoulli) grippers for flat sheet foods. [Online]. Available: http://www.grimsby.ack.uk/documents/frperc/projects/airflow.pdf. 